\title{
Reflections of a Political Scientist
}

\author{
Ronald Schmidt, Sr., California State University, Long Beach
}

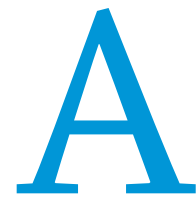

fter informing my colleagues at Davidson College of my plans to retire from college teaching in May 2018, I was asked to give a talk at the induction of new members to the Alpha Iota Upsilon chapter of Pi Sigma Alpha on April 26, 2018. The invitation prompted me to reflect on the meaning and significance of my career in teaching college political science students, a career that began at a California community college in 1966, and that included forty years on the faculty at California State University, Long Beach (1972-2012). The words that follow are the fruit of those reflections.

I feel very privileged to speak today to honor those who have been inducted into the Davidson College chapter of Pi Sigma Alpha. I was inducted into this organization-the UC Berkeley chapter-in 1964, when I was a junior there.

Pi Sigma Alpha was founded to honor those who excel in the discipline of political science, and I want to spend my few minutes speaking to you explaining why I'm proud to be a political scientist, and to invite you too to take pride in being political science majors.

Aristotle once said that political science is the master science of the practical sciences-the sciences that aim to help us to live better lives-which is something you'd never imagine today by taking your cues from our culture. Political science, unlike economics, has no Nobel Prize for its outstanding practitioners. And how many of us were praised by our parents when we told them we were going to major in political science?

Why did Aristotle think that political science is the master science? To put it concisely, because humans are creatures who live in communities, and it is the political dimension of our community life that is the basis for our being able to act together as a community. Without our being able to act together as a political community, there would be no marketplace, hence no science of economics. Without being able to act together as a political community, there would be no money, and again, no science of economics. Socrates famously said, moreover, that without his polis, his political community of Athens, he himself would not even exist because it was through Athens' laws that his parents married, established a household, and helped bring him to adulthood in that particular setting with that particular way of life.

What I'm trying to say is that 52 years of being a political science professor have reaffirmed my early belief that there is no way to advance our lives together to realize and experience wellbeing and excellence without coming to a better understanding of the political nature of human existence. When I was

\footnotetext{
Ronald Schmidt, Sr. is professor emeritus of political science at California State University, Long Beach. He was an adjunct visiting professor of political science at Davidson College from 2013 to 2018. He can be reached at ron.schmidt@ csulb.edu. This essay was originally published in the newsletter of Phi Sigma Alpha.
}

inducted into Pi Sigma Alpha, President John F. Kennedy had been assassinated only a few months before, and I grew to adulthood very much influenced by the Kennedy ethos of public service, which led me to believe that a life of public service, a life of serving the public good, was the highest calling I could imagine.

We now live in a time of deep political crisis, a time in which there is so much polarization, venality and meanspirited animosity in our political institutions that it is easy to imagine leaving it all behind to tend to our individual and private lives and needs. But I believe, and I want to urge you to consider, that there is no escaping a political life for us if we are humans. Humans need each other to flourish, or even to survive beyond a minimal level of existence. Which means that we are interdependent beings. But we are also diverse-we are different from each other in so many ways: we have different ideas, different beliefs, different interests, different temperaments, different desires, different cultural practices that are meaningful to us, different sexualities, and in many, many other ways. The combination of these two basic facts of human life-interdependence and difference-leads inevitably to conflict, and it is in trying to work out a way to live together under these conditions that we find ourselves living and acting politically. Politics, I believe, is nothing more or less than the effort, the work, in which we engage to try to live together as well as we can under conditions of interdependence, difference and conflict. So, there is no escaping politics. We are never going to be, individually, fully self-sufficient beings who have no need of each other, and we are never going to be all the same, without differences, so we are always going to have to practice politics.

Here is where political science comes into play. Political science is the organized effort of trying to better understand how our political communities work-how our political institutions and practices, our political actions and beliefs, operate to manage our communities' interdependencies and manifest differences. In a world such as ours in the year 2018 - where global markets, global technologies, and globally transmitted ideas have generated interdependencies of mind-boggling complexity, and have fostered uncountable and multifaceted ways to experience the conflicts that come from our differences-it is vitally important that we understand what is at stake, and how things work, so that we might apply our minds and hearts to coming up with ways to deal with our interdependencies and differences in ways that enable us to flourish together in our communities.

Aristotle claimed that human beings uniquely have the capacity for speech and reason, and that using our reason/speechlogos-is how we make sense of the world and how we deliberate together on a right course of action aimed at making things better. So, in concluding, I ask that you indulge an old political scientist in sharing my hopes for those of you being honored this afternoon: 
I hope that you will be a lifelong political scientist in the best sense: that you continue to learn as much as you can about how the world works, and especially the ways in which the political world contributes to, and detracts from, our efforts to and passion, and that you can follow toward self-fulfillment. And then, I hope you will do what you can to help bring people together to make something good happen, again and again and again. And I hope that you don't ever give up, that you don't ever

We now live in a time of deep political crisis, a time in which there is so much polarization, venality and mean-spirited animosity in our political institutions that it is easy to imagine leaving it all behind to tend to our individual and private lives and needs. But I believe, and I want to urge you to consider, that there is no escaping a political life for us if we are humans.

flourish as individuals and communities. Equally important, I hope you find a "path with heart," a way to live that brings you out of yourself to touch the world around you with wisdom despair, because while we can't know in advance the good that can be done when we work together, we do know that no good will come of not trying.. 